\title{
The Effect of Maternal Obesity on Perinatal and Neonatal Outcomes
}

(D) Miraç Özalp, (D) Veli Mihmanlı

University of Health Sciences Turkey, Prof. Dr. Cemil Taşçıoğlu City Hospital, Clinic of Obstetrics and Gynecology, İstanbul, Turkey

\section{Abstract}

Objective: To investigate the relationship between maternal obesity and perinatal and neonatal outcomes in primigravid pregnant women. Methods: A total of 162 primigravid pregnant women were categorized into four groups based on their body mass index (BMI), age, gravida (number of pregnancies), parity (number of births), gestational week, pre-pregnancy body weight, height, prenatal final body weight, delivery patterns and indications, pre-eclampsia, fetuses small for gestational age (SGA), hemoglobin values at the time of hospitalization and after 24 $\mathrm{h}$ of delivery, transfusional requirements, birth weight of the babies, neonatal intensive care need, and the babies' 1st-5th min APGAR scores were compared among the groups.

Results: No significant differences were noted among the BMI groups in terms of age, gestational age, delivery type, neonatal intensive care unit needs, and transfusional requirements. The weights of the babies, weight gain during the pregnancy, incidence of pre-eclampsia, incidence of SGA, and APGAR scores were found to be statistically significantly different among the groups.

Conclusion: The findings of the present study indicate that maternal obesity is an important factor for increasing risk of pregnancy complications and neonatal morbidity.

Keywords: Obesity, maternal outcomes, perinatal outcomes, pre-eclampsia, small for gestational age

\section{INTRODUCTION}

Obesity is a disease characterized by increased body fat tissues (1). It is a common health problem across the world, with increasing incidence reported among women of the reproductive age (1). Obesity was initially accepted as a problem of the developed countries, but its prevalence has gradually spread across the world, irrespective of the east-west or rich-poor situation, in parallel with the increasing income levels in the developing countries with the adoption of the western lifestyle, increased energy intake, decreased energy expenditure, and, finally, the rural-to-urban immigration phenomena (2). With reference to the definition of obesity by the World Health Organization (WHO) in 1995 and 2000 and as updated in 2004, it can be classified in the context of body mass index (BMI). BMI is a simple measure used to define a person as underweight, normal-weight, overweight, or obese by using the relationship between weight and length in adult individuals. BMI is calculated by dividing the body weight in kilograms into the square of the length in meters (expressed in $\left.\mathrm{kg} / \mathrm{m}^{2}\right)(1)$.

Pregnancy is marked by a period of rapid body weight changes, and uncontrolled increases or decreases in weight during this period could result in critical health concerns for the mother as well as the fetus (3). Recommendations for weight gain during pregnancy aim at the best outcome of pregnancy in terms of mother and baby $(3,4)$. In 2009, the American Institute of Medicine (IOM) published a recommendation guide to regulate the weight gain based on different BMI levels in pregnancy, in accordance with the WHO's classification of obesity (5). Pregnant 
obese women face risks such as gestational diabetes, hypertensive diseases, thromboembolism, preterm labor, macrosomia, birth complications, and increased rate of cesarean (C/S) delivery (5).

This study aimed to investigate the relationship between maternal obesity and perinatal and neonatal outcomes among primigravid pregnant women.

\section{METHODS}

The present study is a prospective observational study on 162 primigravid pregnant women admitted to the Emergency Delivery Room of Okmeydanı Training and Research Hospital between 01.01.2015 and 30.04.2015. The research was approved by the Ethics Committee of Okmeydanı Training and Research Hospital (23.12.2014; no: 256). The information on pregnancy age, gravida (number of pregnancies), parity (number of births), gestational week, pre-pregnancy body weight, length, BMI, prenatal final body weight, delivery patterns and indications, incidence of pre-eclampsia, and fetuses who were small for gestational age (SGA) according to the gestational week, hemoglobin $(\mathrm{Hb})$ values at the time of hospitalization and after $24 \mathrm{~h}$ of delivery, transfusional requirements, birth weight (BW) of babies, neonatal intensive care need, and the babies' 1 st-5th min APGAR scores were obtained from the subjects' medical files. The subjects were accordingly categorized into 4 different BMI groups that were then compared for different parameters. The underweight group had $\mathrm{BMI}<18.5 \mathrm{~kg} / \mathrm{m}^{2}$, the normal group had BMI: $18.5-24.9 \mathrm{~kg} / \mathrm{m}^{2}$, the overweight group had BMI: $25-29.9 \mathrm{~kg} / \mathrm{m}^{2}$, and the obese group had BMI $>30 \mathrm{~kg} / \mathrm{m}^{2}$. SGA refers to a child born with BW and/or birth length under two standard deviations for the gestational age and sex of the population. All pregnant women who wished to participate in the study were informed about the research goals, and their written informed consents were obtained. Pregnant women with pre-pregnancy chronic internal or surgical diseases or with multiple pregnancies and who happened to have fetuses with an anomaly detected during the screening were excluded from the study, and the remaining primigravid pregnant women were included.

\section{Statistical Analysis}

The number cruncher statistical system (NCSS) 2007 software (Kaysville, Utah, USA) was used for statistical analysis. When evaluating the study data, One-Way analysis of variance was used to compare among three or more groups with normal distribution in comparison with quantitative data and Tukey's honestly significant difference test for the determination of the group causing differences used alongside descriptive statistical methods (such as mean, standard deviation, median, frequency, ratio, minimum, and maximum). The Kruskal-Wallis test was applied for the comparison of 3 or more groups with no normal distribution, while the Mann-Whitney $U$ test was used for the determination of the group causing the difference. Pearson's chisquare test and Fisher-Freeman-Halton Exact test were used for comparison of the qualitative data. Significance was evaluated at $p<0.01$ and $p<0.05$.

\section{RESULTS}

The ages of the pregnant women included in the study ranged from 18 to 42 years, with the mean value of $27.15 \pm 5.03$ years. Examination of the weight of the pregnant women revealed a range of $43-107 \mathrm{~kg}$ (mean: $65.16 \pm 11.76 \mathrm{~kg}$ ), while the height of the pregnant women was $145-180 \mathrm{~cm}$ (mean: $161.72 \pm 7.69 \mathrm{~cm}$ ), and the BMI values were $16.81-43.97 \mathrm{~kg} / \mathrm{m}^{2}$ (mean: $25.20 \pm 5.56$ $\left.\mathrm{kg} / \mathrm{m}^{2}\right)$ (Table 1).

The gestational period of the subjects ranged from 28 to 42.71 weeks (mean duration: $38.46 \pm 2.26$ weeks). The weight of their babies ranged from 1.185 to 4.800 g (average: $3212.59 \pm 672.28$ g) (Table 2).

The gain in the weight of the pregnant women ranged between 3 and $22 \mathrm{~kg}$ (mean gain value: $10.78 \pm 2.80 \mathrm{~kg}$ ). In terms of the birth type, normal spontaneous birth (NSB) was recorded for $46.9 \%(n=76)$, while cesarean (C/S) birth was recorded for $53.1 \%$ $(n=86)$ of the subjects.

No significant difference was noted among the BMI groups in terms of age, gestational age, delivery type, neonatal intensive care unit (ICU) needs, and transfusional requirements (Table 3).

Among the BMI groups, it was observed that the weights of the babies of obese pregnant women were significantly higher than those of underweight, normal-weight, and overweight pregnant women ( $p=0.003 ; p=0.046 ; p=0.049$, respectively).

Among the BMI groups, the weight gain among the underweight pregnant women were found to be significantly greater than that among the overweight and obese pregnant women $(p=0.001$; $p=0.001$, respectively).

Table 1. Findings related to the maternal characteristics

\begin{tabular}{|l|l|l|}
\hline & Minimum-maximum & Mean \pm SD \\
\hline Age (years) & $18-42$ & $27.15 \pm 5.03$ \\
\hline Weight $(\mathrm{kg})$ & $43-107$ & $65.16 \pm 11.76$ \\
\hline Length $(\mathrm{cm})$ & $145-180$ & $161.72 \pm 7.69$ \\
\hline Body mass index $\left(\mathrm{kg} / \mathrm{m}^{2}\right)$ & $16.81-43.97$ & $25.20 \pm 5.56$ \\
\hline SD: Standard deviation & \multicolumn{2}{|l}{} \\
\hline
\end{tabular}


The evaluation of the incidence of pre-eclampsia revealed statistically significantly lower incidence in the underweight pregnant women than in the overweight and obese pregnant women ( $p=0.008 ; p=0.030$, respectively).

Examination of the BMI groups revealed that the rate of SGA incidence in babies of underweight pregnant women was significantly greater than that of obese pregnant women $(p=0.006)$.

Finally, on comparison of the APGAR scores, 1 st-min APGAR scores of babies of the normal group and the $5^{\text {th }}$-min APGAR scores of the babies of the underweight group were significantly greater than those of the overweight and obese groups $(p=0.045$, $\mathrm{p}=0.025)$.

\section{DISCUSSION}

Dramatic differences have been recorded in the recommendations made to the women about body weight gain during pregnancy when compared to that 60 years ago. Past studies have shown that body weight gain in pregnancy is related to maternal characteristics such as BMI at the onset of pregnancy, age, parity, education level, the ethnic group as well as the sociodemographic characteristics (6-8). In a study conducted by Marshall et al. (9) on 64,272 pregnant women, $82.5 \%$ of the subjects were found to be obese according to their BMI and $15.6 \%$ of them belonged to the morbidly obese group and $1.8 \%$ to the super obese group. In our study, 162 pregnant women were examined prospectively, and the mean body weight of these women before their pregnancies was found to be $65.16 \pm 11.76 \mathrm{~kg}$, the mean height was $161.72 \pm 7.69 \mathrm{~cm}$, and the mean BMI at the onset of pregnancy was $25.20 \pm 5.56 \mathrm{~kg} / \mathrm{m}^{2}$. When the cases were divided into 4 baseline BMI groups, $23.2 \%(n=37)$ of the pregnant women were recorded as underweight, $25.9 \%(n=42)$ as normalweight, $26.5 \%(n=43)$ as overweight, and $24.6 \%(n=40)$ as obese. However, this study was a single-centered study conducted on a small population, which limits consideration of its inference to diverse populations.

As per the IOM-2009 recommendation, the body weight gain should be in the range of 12.6-18.1 kg for the underweight, 11.3$15.9 \mathrm{~kg}$ for the normal-weight, $6.8-11.3 \mathrm{~kg}$ for the overweight, and $5.0-9.1 \mathrm{~kg}$ for the obese pregnant women (5). A study by DeVader et al. (10) reported 94,696 pregnant women with a normal BMI, of which $60 \%$ of the pregnant women did not have a recommended body weight gain, $17.2 \%$ of the body weight was less than the recommended value by $10 \mathrm{M}$, and $42.8 \%$ of the body weight was higher than the recommended value. In this study, however, it was found that subjects in the underweight group gained $12.65 \mathrm{~kg}$, those in normal group gained $11.37 \mathrm{~kg}$, those in the overweight group gained $10.10 \mathrm{~kg}$, and those in the obese group gained $9.19 \mathrm{~kg}$; these increases in the weight gain were consistent with the IOM recommendations. We noted that the gained weights of the pregnant women in the underweight and

\begin{tabular}{|c|c|c|c|c|c|c|}
\hline \multirow{2}{*}{\multicolumn{2}{|c|}{ Mean \pm SD }} & Underweight $(n=37)$ & Normal $(n=42)$ & Overweight $(n=43)$ & Obese $(n=40)$ & \multirow[t]{2}{*}{ ap } \\
\hline & & Mean \pm SD & Mean \pm SD & Mean \pm SD & & \\
\hline \multicolumn{2}{|c|}{$\begin{array}{l}\text { Birth weight }(\mathrm{g}) \\
\text { Weight gain during pregnancy }(\mathrm{kg})\end{array}$} & $\begin{array}{l}3005.95 \pm 514.50 \\
12.65 \pm 2.43\end{array}$ & $\begin{array}{l}3149.62 \pm 511.16 \\
11.37 \pm 2.17\end{array}$ & $\begin{array}{l}3158.49 \pm 791.12 \\
10.10 \pm 2.80\end{array}$ & $\begin{array}{l}3528.00 \pm 722.97 \\
9.19 \pm 2.58\end{array}$ & $\begin{array}{l}0.004^{* *} \\
<0.001^{* * *}\end{array}$ \\
\hline \multirow{2}{*}{ Birth type } & NSD & $22(59.5)$ & $19(45.2)$ & $20(46.5)$ & $14(35.0)$ & \multirow{2}{*}{ c0.199 } \\
\hline & $\mathrm{C} / \mathrm{S}$ & $15(40.5)$ & $23(54.8)$ & $23(53.5)$ & $26(65.0)$ & \\
\hline
\end{tabular}

\begin{tabular}{|c|c|c|c|c|c|}
\hline & $\begin{array}{l}\text { Underweight } \\
(n=37)\end{array}$ & $\begin{array}{l}\text { Normal } \\
(n=42)\end{array}$ & $\begin{array}{l}\text { Overweight } \\
(n=43)\end{array}$ & $\begin{array}{l}\text { Obese } \\
(n=40)\end{array}$ & $\mathbf{p}$ \\
\hline Pre-eclampsia & $1(2.7)$ & $6(14.3)$ & $10(23.3)$ & $8(20.0)$ & $\mathrm{d} 0.040^{*}$ \\
\hline Small for gestational age & $9(24.3)$ & $6(14.3)$ & $5(11.6)$ & $1(2.5)$ & $\mathrm{d} 0.033^{*}$ \\
\hline Neonatal intensive care need & $10(27.0)$ & $4(9.5)$ & $12(27.9)$ & $11(27.5)$ & ${ }^{c} 0.126$ \\
\hline
\end{tabular}


normal-weight groups were statistically significantly higher than those in the overweight and obese groups $(p=0.001 ; p=0.001$, respectively).

Another criterion investigated in the study was the relationship between the maternal BMI and newborn weights. In the Baeten's series, infant birth rates of $>4000$ g were $10.7 \%$ in 50,378 cases with normal BMI, $14.5 \%$ in 17547 cases with high BMI, and 17.3\% in 9.806 cases with very high BMI; the macrosomic infant birth rate in obese pregnant women was found to be significantly higher (11). The results of this study indicate that the mean birth weight of babies was $3005.95 \mathrm{~g}$ in the underweight BMI group, $3149.62 \mathrm{~g}$ in the normal-weight group, $3158.49 \mathrm{~g}$ in the overweight group, and $3528.00 \mathrm{~g}$ in the obese group. Statistically significant difference was noted among the groups in terms of the weight of newborns $(p=0.004)$. The comparison of the birth weeks among the 4 groups based on the BMI revealed that the mean birth weeks were 38.6, 38.3, 38.1, and 38.7 for the normal, overweight, and obese groups, respectively. No statistically significant difference was noted among the BMI groups in terms of the gestational weeks $(p>0.05)$. In a study conducted by Vinturache et al. (12) in Canada in 2015 on 3.388 pregnant women, the mean birth weeks of $62.5 \%$ of the subjects in the normal-weight group were found to be 390/7-406/7 weeks (accepted as "term"), those in the subjects in the overweight group were 410/7-416/7 weeks ("late period"), and those of subjects in the obese group were 370/7-386/7 ("early period"). In this study, the smaller sample size was deemed attributable for these differences.

The NSB rate was found to be $46.9 \%(n=76)$ and the $C / S$ delivery rate $53.1 \%(n=86)$ in all cases. The NSB rate for all groups were $59.5 \%, 45.2 \%, 46.5 \%$, and $35 \%$ for the underweight, normal, overweight, and obese groups, respectively. In addition, the C/S delivery rates were $40.5 \%, 54.8 \%, 53.5 \%$, and $65 \%$ in the underweight, normal-weight, overweight, and obese groups, respectively. In this study, no statistically significant difference was recorded between the birth types based on the BMI groups. When we examined the study with the large database of Baeten et al. (11), we noted that the C/S delivery rate was $16.6 \%$ among 50,425 pregnant women with normal BMI, $23.2 \%$ among 17,571 pregnant women with high BMI, and 32\% among 9.817 pregnant women with very high BMI. The reasons for the lack of a statistically significant result in this series can be attributed to the small number of patients involved and that the study hospital was a tertiary center.

When the results obtained were examined in terms of pregnancyrelated cases of hypertension and pre-eclampsia, the respective risk ratio were found to be $2.7 \%$ in underweight, $14.3 \%$ in normal-weight, $23.3 \%$ in overweight, and $20 \%$ in obese patients. It should be emphasized that this risk increase was not only seen in obese women with very high BMI ( 230$)$ but also in overweight women with BMI 25-29.9. In the study of Kılık et al. (13) in 2019, no significant difference was noted in the BMI between a pre-eclampsia group $\left(30.6 \pm 5.6 \mathrm{~kg} / \mathrm{m}^{2}\right)$ and the control group $\left(31.0 \pm 4.2 \mathrm{~kg} / \mathrm{m}^{2}\right)$. But this past study includes a very small study population. In another study by Young et al. (14) conducted in 2016, the incidence of hypertensive disease in pregnancy was $7.2 \%$ and that of pre-eclampsia was $0.09 \%$ in a group of subjects with $\mathrm{BMI}<30$, while the corresponding ratios were $14.5 \%$ and $0.22 \%$ in the group with BMI $>30$, respectively. Kumari (15) reported pregnancy-related hypertension rates of $28.7 \%$ in 188 obese patients, while this rate was 3\% in the control group (BMI 20-25); the difference herein was statistically significant. The results of these past studies are in line with the present findings supporting that pregnancy-related hypertension is an important risk factor both in overweight and obese pregnant women. Thus, it is extremely important that hypertensive diseases be included among the most important causes of maternal mortality. Another fetal-neonatal variable examined in our study was the SGA development rates. The SGA incidence rates were revealed to be $24.3 \%$ for the underweight group, $14.3 \%$ for the normalweight group, $11.6 \%$ for the overweight group, and $2.5 \%$ for the obese group; statistically significant differences were recorded among the BMI groups in terms of the SGA incidence in newborns $(p=0.033)$. In the 2001 series of Sebire et al. (16), the SGA infant birth rates were found to be $5.45 \%$ in the normal BMI group and $4.58 \%$ and $4.76 \%$ in the groups with high and very high BMI, respectively. Examination of the results of studies on this subject revealed that the findings obtained in our series were consistent with those of the literature.

In our study, the postoperative $1^{\text {st }}$ and $5^{\text {th }}$-min APGAR scores were evaluated for $4 \mathrm{BMI}$ groups as another fetal-neonatal criterion. These 4 groups were compared in terms of low APGAR scores. The mean 1st-min and 5th APGAR scores were 7.27 and 8.78 in the underweight group, 7.69 and 8.74 in the normalweight group, 6.83 and 8.00 in the overweight group, and 6.78 and 8.33 in the obese group, respectively. There was a statistically significant difference among the BMI groups in terms of both the 1 st-min APGAR scores $(p=0.045)$ and the $5^{\text {th }}$-min APGAR scores $(p=0.025)$. When we examined the study of Bianco et al. (17) published in 1998, we noted that the ratio of babies with APGAR score $<7$ at the $5^{\text {th }}$ min was $0.7 \%$ in 613 morbidly obese pregnant women and $0.4 \%$ in 11,313 control pregnant women. Although the author did not detect any statistically significant 
difference, the birthrate of newborns with low APGAR scores was higher in the morbidly obese group. The results of these past studies were found to be consistent with those obtained in our series. The incidence of low APGAR score was found to be higher in children born from obese pregnant women than in those born from normal-weight pregnant women.

The last fetal-neonatal parameter evaluated was to examine the follow-up rates of infants in the neonatal ICUs among all 4 BMI groups. The need for neonatal ICU after birth was 10\% in the underweight group, $9.5 \%$ in the normal-weight group, $11.6 \%$ in the overweight group, and $12.7 \%$ in the obese group. No statistically significant difference was noted among the 4 groups. Because the incidences of pregnancy complications were higher in the overweight and obese pregnant women, their newborns showed more frequent cases of transient tachypnea and respiratory distress, and the rate of neonatal follow-up in the premature ward was higher, with the number of hypoglycemic newborns being higher due to the higher rate of gestational diabetes and the larger size of the baby at birth. SGA emerged as the leading newborn ICU requirement of babies of pregnant women in the underweight group.

In our study, $\mathrm{Hb}$ values at the time of admission and that at the 24th $\mathrm{h}$ after birth as well as the blood transfusional requirements of the subjects were also examined. The mean $\mathrm{Hb}$ value at admission was 11.99 and the mean postpartum $\mathrm{Hb}$ was 10.28 in the underweight group, while it was 11.58 and 9.94 in the normal group, 12.15 and 10.33 in the overweight group, and 12.53 and 10.97 in the obese group, respectively. Statistically significant difference was noted among the BMI groups in terms of admission $\mathrm{Hb}$ values $(p=0.023)$. In addition, statistically significant difference was noted among the BMI groups in terms of the $\mathrm{Hb}$ values at the 24th hour after birth $(p=0.032)$. The blood transfusion rates were found to be $10.8 \%$ in the underweight group, $11.9 \%$ in the normal group, $16.3 \%$ in the overweight group, and $12.5 \%$ in the obese group, albeit there was no statistical significance among them.

\section{CONCLUSION}

The findings of the present study suggest that obesity is an important factor that contributes to increasing pregnancy complications and fetal-neonatal morbidity. Therefore, starting a pregnancy with an appropriate BMI is expected to minimize the risk of complications among the mothers and newborn. Moreover, it will also help realize the principles of a healthy mother and a healthy newborn, which are the main objectives of an obstetric intervention.

\section{Ethics}

Ethics Committee Approval: Ethics Committee of Okmeydanı Training and Research Hospital (23.12.2014; no: 256).

Informed Consent: All pregnant women who wished to participate in the study were informed about the research goals, and their written informed consents were obtained.

Peer-review: Externally peer-reviewed.

\section{Authorship Contributions}

Concept: M.Ö., V.M., Design: M.Ö., V.M., Data Collection or Processing: M.Ö., Analysis or Interpretation: M.Ö., V.M., Literature Search: M.Ö., Writing: M.Ö.

Conflict of Interest: No conflict of interest was declared by the authors.

Financial Disclosure: The authors declared that this study received no financial support.

\section{REFERENCES}

1. Obesity: peventing and managing the global epidemic. Report of a WHO Consultaion. World Health Organ Tech Rep Ser 2000;894:i-xii,1-253.

2. Public Health Agency of Canada. Obesity in Canada: A joint report from the Public Health Agency of Canada and the Canadian Institute for Health Information. Report No. Cat.: HP5-107/2011.

3. Davies GA, Maxwell C, McLeod L. SOGC maternal fetal medicine committee. Obesity in pregnancy. Sogc clinical practice guideline. J Obstet Gynaecol Can 2010;32:165-73.

4. Crane JM, White J, Murphy P, Burrage L, Hutchens D. The effect of gestational weight gain by body mass index on maternal andneonatal outcomes. J Obstet Gynaecol Can 2009;31:28-35.

5. Institute of Medicine. Weight Gain During Pregnancy: Reexamining the Guidelines. Washington, DC: National Academies Press; 2009.

6. Olson CM. Strawderman MS. Modifiable behavioral factors in a biopsychosocial model predict inadequate and excessive gestational weight gain. Journal of the American Dietetic Association 1999;94:616-22.

7. Brawarsky P, Stotland NE, Jackson RA, Fuentes-Afflick E, Escobar GJ Rubashkin $N$, et al. Pre-pregnancy and pregnancy-related factors and the risk of excessive or inadequate gestational weight gain. Int J Gynaecol Obstet 2005;9:125-31.

8. Howie GJ, Sloboda DM, Kamal T, Vickers MH. Maternal nutritional history predicts obesity in adult offspring independent of postnatal diet. J Physiol 2009;15;587:905-15

9. Marshall NE, Guild C, Cheng YW, Caughey AB, Halloran DR. Maternal superobesity and perinatal outcomes. Am J Obstet Gynecol 2012;206:417. e1-6.

10. DeVader SR, Neeley HL, Myles T, Leet TL. Evaluation of gestational weight gain guidelines for women with normal prepregnancy body mass index. Obstet Gynecol 2007:110:745-51.

11. Baeten J, Bukusi E, Lambe M. Pregnancy complications and outcomes among overweight and obese nulliparous women. Am J Public Health 2001;91:436-40. 
12. Vinturache AE, McDonald S, Slater D, Suzanne T. Perinatal outcomes of materrnal overweight and obesity in term infants: a population-based cohort study in Canada. Scientific Report, 2015.

13. Kılık T, Mihmanlı V, Çetin SN, Șahin O, Demirayak G, Bulut B. Comparison of maternal serum soluble Fms-like tyrosine kinase-1/placental growth factor ratio in preeclamptic and normotensive pregnant women. Eur Arc Med Res 2019;35:98-101.

14. Young OM, Twedt R, Catov JM. Pre-pregnancy maternal obesity and the risk of preterm preeclampsia in the Americanprimigravida. Obesity (Silver Spring) 2016;24:1226-9.
15. Kumari AS. Pregnancy outcome in women with morbid obesity. Int J Obstet Gynecol 2001;73:101-7.

16. Sebire NJ, Jolly M, Harris JP, Wodsworth J, Beard RW, Regan L, et al. Maternal obesity and pregnancy outcome: a study of 287213 pregnancies in London. Int J Obes Relat Metab Disord 2001;25:1175-82.

17. Bianco AT, Smilen SW, Davis Y, Lopez S, Lapinski R, Lockwood CJ. Pregnancy outcome and weight gain recommendations for the morbidly obese woman. Obstet Gynecol 1998;91:97-102. 